\title{
A Rare History: an Intracranial Nail Present for Over a Half-Century
}

\author{
Ozkan Durmaz ${ }^{1}$, Ali Karadage,*, Fusun Demircivi Ozer², Mahmut Camlar², Erik H. Middlebrooks³, \\ Baran Bozkurt ${ }^{4}$, Mehmet Senoglu²
}

\begin{abstract}
We present a rare case of a patient with a persistent headache for many years found to have an intracranial nail present for nearly 65 years. The nail was found entering approximately $1 \mathrm{~cm}$ from the midline on the left side, passing below the superior sagittal sinus, with the tip $1.5 \mathrm{~mm}$ right of the frontal horn of the lateral ventricle. Treatment strategies designed to optimize outcome for intracranial foreign bodies and possible complications are discussed in this report. We also discuss the decision for surgical intervention for foreign bodies and the relevance of position of the foreign body.
\end{abstract}

KEYWORDS

nail; penetrating injury; headache; intracranial

\section{AUTHOR AFFILIATIONS}

${ }^{1}$ Kars Harakani Public Hospital, Department of Neurosurgery, Kars, Turkey

${ }^{2}$ Tepecik Research and Training Hospital, Department of Neurosurgery, Izmir, Turkey

${ }^{3}$ MD. Department of Radiology, Mayo Clinic, Jacksonville, FL, USA

${ }^{4}$ University of Minnesota, Department of Neurosurgery, Minneapolis, MN, USA

* Department of Neurosurgery, Tepecik Research and Training Hospital, Izmir, Turkey; e-mail: egealikaradag@gmail.com

Received: 11 January 2017

Accepted: 28 June 2017

Published online: 5 February 2018

Acta Medica (Hradec Králové) 2017; 60(3): 124-126

https://doi.org/10.14712/18059694.2018.5

(C) 2017 The Authors. This is an open-access article distributed under the terms of the Creative Commons Attribution License (http://creativecommons.org/licenses/by/4.0), which permits unrestricted use, distribution, and reproduction in any medium, provided the original author and source are credited. 


\section{INTRODUCTION}

In the general public, penetrating injuries are less common than many other traumatic injuries, such as blunt trauma $(1,2)$. The incidence of penetrating skull and head injuries is $\sim 0.4 \%$ of all head injuries. It has been estimated that penetrating injuries from nails constitute $33.3 \%$ of all penetrating injuries (3). Penetrating injuries are commonly accidental, but inflicted injuries, such as stabbings, firearm injuries, homicide, or suicide attempts are also encountered (4). Penetrating head injuries due to a foreign body may result in no lasting neurologic deficit but frequently result in significant morbidity or mortality. The complications can range from intracerebral hematoma, intraventricular hemorrhage, cerebral contusion, pneumocephalus, brain stem injury and carotid sinus fistula, amongst others (5-7). Injuries to the intracerebral vasculature and infections are the major cause of death (8-10). Our case is interesting because the patient lived more than half of a century with a nail in her brain with persistent headaches being the only symptom.

\section{CASE REPORT}

We report the case of a 66-year-old female admitted to neurosurgery with persistent headaches for nearly 65 years. Her family reported no known accidents or head traumas throughout her life. At the time of admission, the findings included persistent frontoparietal headache, blood pressure of 125/75 mmHg, pulse rate of 82 beats/min (bpm), respiratory rate of 20 breaths/min, and body temperature of $37.1^{\circ} \mathrm{C}$. She was conscious, cooperative, and well oriented to time, place, and person with no weakness or neurological deficits. Routine laboratory results were normal.

Computed tomography (CT) of the head without contrast was performed, which revealed the presence of a linear, metallic foreign body nearly $4.5 \mathrm{~cm}$ in length. On physical examination, the nail was not palpable under the scalp. The coronal CT images of the brain show the nail penetrating the frontal lobe through approximately $4.5 \mathrm{~cm}$ of brain parenchyma (Figure 1A). The nail entered nearly $1 \mathrm{~cm}$ from the midline on the left side of the frontal lobe. It crossed the falx cerebri obliquely under the superior sagittal sinus and reached the frontal horn of the right lateral ventricle. The distance between the tip of the nail and the anterior edge of the frontal horn, as seen on sagittal CT images, was $1.5 \mathrm{~mm}$ (Figure $1 \mathrm{~B}$ ). The nail is also shown on a skull radiograph as a $4.5 \mathrm{~cm}$ metallic foreign body entering the calvarium through the left frontal bone (Figure 1C).

Following the CT, we hospitalized the patient and completed the preparations for surgery. We made a burr-hole near the nail inlet and extended it. A mini-dura-mater incision was made and overthrown to the midline. Following this incision, the nail (Figure 1D) was visualized and removed. The dura-mater and skin were sutured. Postoperative head CT showed the presence of small metal-density fragments in the area of the removed nail (Figure 2). Given the appearnce of the removed nail, this was felt to represent small corroded and rusted debris from this old nail. The patient was placed on antibiotics (ciprofloxacin and

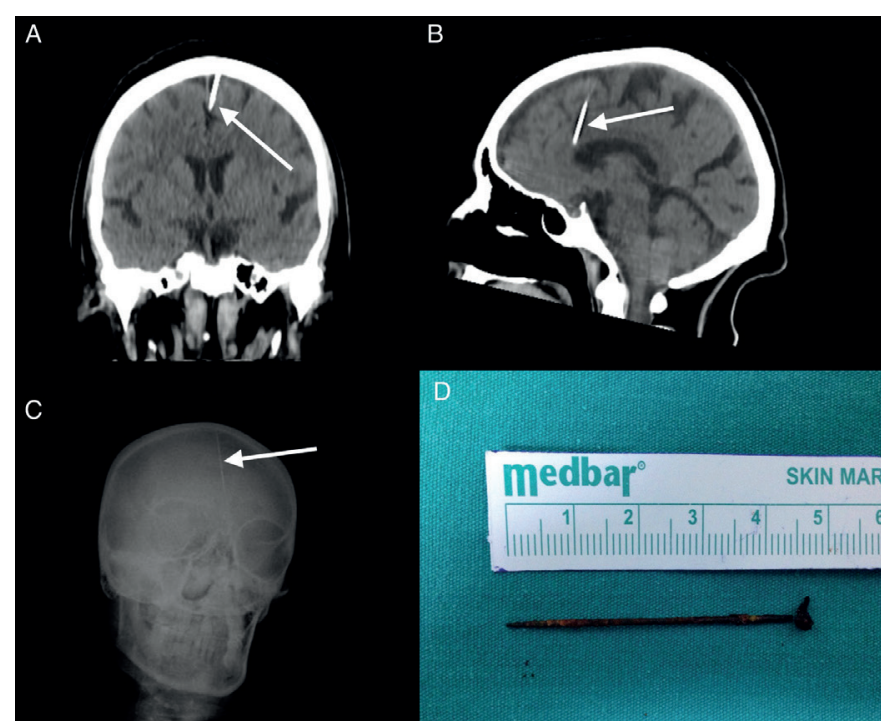

Fig. 1: Preoperative CT scan images in the coronal (A) and sagittal (B) plane show the course of the intracranial nail (arrow). AP radiograph (C) also illustrates the relationship of the nail (arrow) with the skull. The nail (D) was surgically removed through a burr hole.

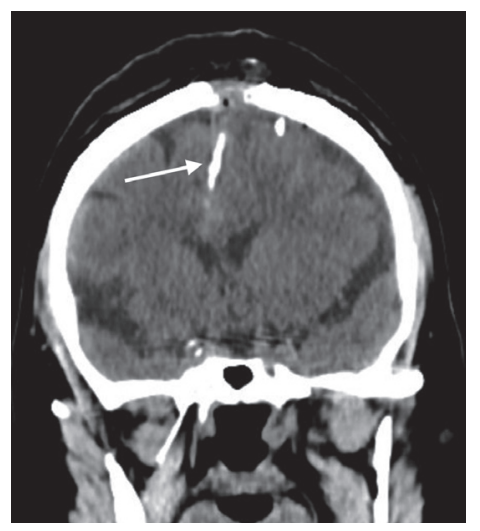

Fig. 2: Postoperative coronal CT image shows postoperative changes from burr hole and nail removal with residual metallic debris within the area of nail removal (arrow). The was felt to be from small corroded and rusted metal fragments.

ceftriaxone) and followed up 2 weeks post-operatively. She was in good condition and did not have any neurological deficit on examination. Her headache gradually resolved.

\section{DISCUSSION}

Penetrating injuries are most commonly accidental and only sporadically reported (11). Less frequently, these injuries are a result of attempted suicide, stab and goneshot wounds, a nail wound to the head, armed conflict in civilian/military areas, child abuse, or attempted infanticide $(12,13)$. This study reports an interesting case of a nail in the intracranial cavity for more than half of a century. In the absence of known head trauma, and based on patient discussion, it was hypothesized that our case was the result of a form of infanticide wherein a foreign body is inserted through the fontanelle into the brain (14).

An interesting observation from our case is the absence of serious complications or neurological symptoms despite the presence of a metallic foreign body in her brain for approximately 65 years. The only symptom was a persistent headache. Imaging revealed that the tip of the nail was lo- 
cated near the edge of the right lateral ventricle without breach of the ventricular wall. It is possible that the lack of penetration of the non-sterile nail into the cerebrospinal fluid circulation reduced the likelihood of disseminated central nervous system infection (15).

Surgical management of intracranial foreign bodies is not straightforward and must be assessed on a caseby-case basis $(16,17)$. The standard management of penetrating intracranial injury is to fully assess the depth and location of the penetrating object with imaging, followed by a decision whether surgery is appropriate. The most important concern with penetrating intracranial objects is the potential injury to vascular structures. The treatment, whether surgical or not, should always include antibiotic treatment (7). Prophylactic use of antiepileptic drugs is controversial (18).

In our case, we believed surgery to be appropriate since the patient experienced persistent symptoms of headache. The aim of our surgery was maximum protection of neural function with minimization of complications. Based on previously discussed surgical consideration, we believed the risk of complications was low given the location and suspected ease of removal of this foreign body. The potential for surgical risk and perceived benefit must be weighed closely in such cases. Patients should be informed about the potential outcomes and allowed to make the final decision. In our case, the patient elected surgical intervention, which resulted in no neurologic complications and reduction in the patient's symptoms.

\section{REFERENCES}

1. Bozzeto-Ambrosi P, Costa LF, Azevedo-Filho H. Penetrating screwdriver wound to the head. Arquivos de Neuro-psiquiatria 2008; 66(1): 93-5.

2. Croft AM, Ferllini R. Macroscopic characteristics of screwdriver trauma. Journal of Forensic Sciences 2007; 52(6): 1243-51.
3. Gennarelli TA, Champion HR, Sacco WJ, Copes WS, Alves WM. Mortality of patients with head injury and extracranial injury treated in trauma centers. The Journal of Trauma 1989; 29(9): 1193-201; discussion 201-2.

4. Buczek M, Pieninski A. [Deep penetrating brain injury with 20 years of asymptomatic survival: a case report]. Otolaryngologia polska = The Polish Otolaryngology 1993; 47(6): 553-6.

5. Fallon MJ, Plante DM, Brown LW. Wooden transnasal intracranial penetration: an unusual presentation. The Journal of Emergency Medicine 1992; 10(4): 439-43.

6. Fujimoto S, Onuma T, Amagasa M, Okudaira Y. [Three cases of an intracranial wooden foreign body]. No shinkei geka Neurological surgery 1987; 15(7): 751-6.

7. Hansen JE, Gudeman SK, Holgate RC, Saunders RA. Penetrating intracranial wood wounds: clinical limitations of computerized tomography. Journal of Neurosurgery 1988; 68(5): 752-6.

8. Musa BS, Simpson BA, Hatfield RH. Recurrent self-inflicted craniocerebral injury: case report and review of the literature. British Journal of Neurosurgery 1997; 11(6): 564-9.

9. Rezai AR, Lee M, Kite C, Smyth D, Jafar JJ. Traumatic posterior cerebral artery aneurysm secondary to an intracranial nail: case report. Surgical Neurology 1994; 42(4): 312-5.

10. Litvack ZN, Hunt MA, Weinstein JS, West GA. Self-inflicted nail-gun injury with 12 cranial penetrations and associated cerebral trauma. Case report and review of the literature. Journal of Neurosurgery 2006; $104(5): 828-34$.

11. Ohaegbulam SC, Ojukwu JO. Unusual craniocerebral injuries from nailing. Surgical Neurology 1980; 14(5): 393-5.

12. Large $M$, Babidge N, Nielssen O. Intracranial self-stabbing. Am J Forensic Med Pathol 2012; 33(1): 13-8.

13. Summers WC. The Chinese Nail Murders: forensic medicine in Imperial China. Yale J Biol Med 1999; 72(6): 409-19.

14. Notermans NC, Gooskens RH, Tulleken CA, Ramos LM. Cranial nerve palsy as a delayed complication of attempted infanticide by insertion of a stylet through the fontanel. Case report. Journal of Neurosurgery 1990; 72(5): 818-20.

15. Sedney CL, Harshbarger T, Orphanos J, Collins JJ. Penetrating injury to the superior sagittal sinus by a nail in a 4-year-old child: a case report. Pediatric Emergency Care 2012; 28(11): 1220-3.

16. Mathew JE, Sharma A. Bizarre depressed skull fracture by a tile fragment in a young child, causing superior sagittal sinus injury. Surgical Neurology International 2010; 1: 52.

17. Sani S, Jobe KW, Byrne RW. Successful repair of an intracranial nailgun injury involving the parietal region and the superior sagittal sinus. Case report. Journal of Neurosurgery 2005; 103(3): 567-9.

18. Antiseizure prophylaxis for penetrating brain injury. The Journal of Trauma 2001; 51(2 Suppl): S41-3. 